\title{
Assimilation of oceanic observations in a global coupled Earth system model with the SEIK filter
}

\author{
Sebastian Brune ${ }^{\mathrm{a}, *}$, Lars Nerger ${ }^{\mathrm{b}}$, Johanna Baehr ${ }^{\mathrm{a}}$ \\ ${ }^{a}$ Institute of Oceanography, CEN, Universität Hamburg, Hamburg, Germany \\ ${ }^{b}$ Alfred Wegener Institute, Helmholtz Center for Polar and Marine Research, \\ Bremerhaven, Germany
}

revised version submitted to Ocean Modelling, July 31st, 2015

\section{Abstract}

We present results from the assimilation of observed oceanic 3-D temperature and salinity fields into the global coupled Max Planck Institute Earth system model with the SEIK filter from January 1996 to December 2010. Our study is part of an effort to perform and evaluate assimilation and prediction within the same coupled climate model without the use of re-analysis data. We use two assimilation setups, one where oceanic observations over the entire water column are assimilated, and one where only oceanic observations below $50 \mathrm{~m}$ depth are assimilated. We compare the results from both assimilations with an unconstrained control experiment. While we do not find significant improvements due to assimilation in terms of the root-meansquare error of simulated temperature, 0-700 m heat content, sea surface height (SSH), and the Atlantic meridional overturning circulation (AMOC) against observations, we find the variability in terms of correlation with observations significantly improved due to assimilation, most prominently in the tropical oceans. Improvements over the control experiment are stronger

\footnotetext{
*Corresponding author

Email address: sebastian.brune@uni-hamburg.de (Sebastian Brune)
} 
in the sub-50 $\mathrm{m}$ assimilation experiment and in integrated quantities (SSH, $\mathrm{AMOC})$.

Keywords: oceanic data assimilation, EnKF, seasonal-to-decadal

prediction, Earth system modelling, MPI-ESM

\section{Introduction}

2

The natural variability of Earth's climate is influenced by many factors. Their importance varies with the temporal scales associated with the climate under investigation. The ocean influences or may even dominate the climate variability on time scales larger than a few months due to its large heat capacity. Climate predictions on these time scales therefore depend crucially on the representation of the oceanic variability by the chosen global coupled Earth system model (ESM). At seasonal to decadal time scales, the quality of the respective climate prediction is also inherently dependent on the initial conditions (Cox and Stephenson, 2007; Branstator and Teng, 2012), and in particular on a good initialization of the oceanic state prior to prediction. Any initialization should incorporate the available observations of the past state of the ocean. Oceanic observations are, however, still irregularly and sparsely distributed in both time and space, despite the development of such sophisticated profiling programs as Argo (Roemmich et al., 2009). While the accuracy of instruments is sufficiently high, the observation uncertainty depends on the representativeness of the observations. How representative any observation is to the ESM's grid cell it is falling in remains the subject of ongoing research, and only to a certain degree this error can be approximated from large observation data sets (Forget and Wunsch, 2007; Oke and Sakov, 
2008).

Given the limited number of observations and their large uncertainties to represent the variability of the ocean in space and time, it has been argued that even the entire oceanic data base might currently be too small to successfully constrain an ocean model (Pohlmann et al., 2009). Hence, any oceanic reanalysis will represent both the variability seen in the observations, but also the variability native to the model that is constrained by the observations. When aiming to initialize climate predictions, Pohlmann et al. (2009) argued that best results may be gained when both re-analysis (assimilation) and forecast are produced with the same model. Such a model inherent initialization might keep initialization shocks and model drift in forecast mode comparatively small, assuming an assimilation method is employed that does not force the model too far away from it's climatological mean state.

Popular assimilation methods used with temporally and spatially sparse observations are based on the Ensemble Kalman filter (EnKF, Evensen, 1994). All EnKFs have in common that they represent the model's state estimate and its uncertainty by an ensemble of model states. The ensemble makes the assimilation with large-scale numerical models feasible, because the full error covariance matrix is approximated by the ensemble covariance matrix computed from an ensemble of model states. They analyze the ensemble information together with the observation state and uncertainty to produce an updated ensemble representing the optimized model state and uncertainty. EnKFs are also known for their straightforward applicability in sequential data assimilation and potential efficiency when used on parallel computers (Keppenne and Rienecker, 2002). The EnKFs can handle model non-linearity 
to some extent because the covariance matrix is implicitly propagated in time by integrating each ensemble state by the full model. Building on this original Ensemble Kalman filter, alternative types of EnKFs have been proposed for oceanic data assimilation, such as the error subspace transform KF (ESTKF, Nerger et al. (2012)) or the singular evolutive interpolated KF (SEIK, Pham et al. (1998)).

In our study we use the SEIK filter to assimilate subsurface and surface oceanic temperature and salinity observations into the ocean component of the fully coupled global Max Planck Institute Earth System Model (MPIESM). Our approach is partly similar to recent studies by Karspeck et al. (2013), who also assimilated subsurface oceanic data, but only in a loosely coupled version of the Community Climate System Model (CCSM4), and by Counillon et al. (2014), who assimilated sea surface data but no subsurface observations in the fully coupled Norwegian Climate Prediction Model (NorCPM). Our study extends these studies, on the one hand to a fully coupled ESM including a freely running atmosphere, and on the other hand by the use of real subsurface temperature and salinity profiles from the EN3 database (Ingleby and Huddleston, 2007) for the assimilation.

We test two implementation strategies, one where oceanic observations over the entire water column are assimilated, and one where only oceanic observations below $50 \mathrm{~m}$ depth are assimilated, in both cases the atmosphere is unconstrained. The latter strategy may reduce the discrepancies at the ocean-atmosphere boundary, for instance in temperature, which are implicitly introduced when oceanic surface data are assimilated while atmospheric surface data remain unconstrained. We apply the SEIK filter on a monthly 
basis for a time period of 15 years (1996-2010). We use 8 ensemble members, which is considerably smaller than the 30 members used by Counillon et al. (2014). The ensemble size is chosen to both comply with our computational resources and assess the feasibility, technically and scientifically, of the SEIK assimilation within MPI-ESM. However, we are aware that smaller ensemble sizes are prone to larger sampling errors and therefore an increased ensemble size may be necessary in future implementations.

The long-term aim of our effort is a model-inherent initialization of decadal climate predictions as proposed by Pohlmann et al. (2009), and a contribution to the decadal prediction system developed within the German MiKlip project (Pohlmann et al., 2013).

The remainder of this paper is structured as follows: we describe the model, observations and filter characteristics used in our experimental setup in Sec. 2. Results of our experiments for the temperature field, the heat content, the sea surface height and the Atlantic meridional overturning circulation are shown in Sec. 3. We discuss our results and their implications to our future approach in Sec. 4 and conclude this paper with the main findings in Sec. 5 .

\section{Experimental setup}

\subsection{Model and ensemble Kalman filter}

We use the Max Planck Institute Earth system model (MPI-ESM, Giorgetta et al. (2013)), version 1.0.02, which consists of ECHAM6 (Stevens et al. (2013), ECHAM is an acronym for ECMWF, European Centre for MediumRange Weather Forecasts, and Hamburg) for the atmospheric component $\left(\approx 2.5^{\circ}\right.$ horizontal resolution, 47 levels up to $1 \mathrm{hPa}$ ), and MPIOM (Max 
Planck Institute Ocean Model, Jungclaus et al. (2013)) for the oceanic part $\left(\approx 1.5^{\circ}\right.$ horizontal resolution, 40 depth levels), both coupled once a day by OASIS3 (Ocean Atmosphere Sea Ice Soil, Valcke (2013)). In this study we do not apply any atmospheric assimilation nor nudging.

We implement the parallel data assimilation framework PDAF (Nerger and Hiller, 2013, http://pdaf.awi.de) in its offline mode together with the oceanic component MPIOM of MPI-ESM. PDAF has implemented several ensemble Kalman filter sub-types, we use the global SEIK filter in our experiments. As with other ensemble Kalman filters, the process of assimilating observations into MPI-ESM with SEIK can be sub-divided into three steps. Firstly, the forecast, where all ensemble members are independently evolved in time until an observation data set is going to be assimilated, we call this the "assimilation interval". Secondly, the Kalman update of the ensemble members with the observations, which we call the "analysis step". Thirdly, the "reinitialization" of the ensemble based on the updated state and uncertainty from the analysis step. Then the re-initialized ensemble enters the forecast of the next assimilation interval.

In the following we give an abridged description of the global SEIK filter based on Nerger et al. (2006). A detailed description of the SEIK filter and a comparison with other sub-types of the ensemble-based Kalman filters can be found in Nerger et al. (2005).

We assume an already initialized ensemble of states with $\mathrm{N}$ members $(\alpha=$ $1, \ldots, N)$ at time $t_{i}$, with the size of the model state $n$ :

$$
\mathbf{X}_{i}=\left\{\mathbf{x}_{i}^{\alpha}\right\} \in \mathbb{R}^{n \times N}
$$


The non-linear model independently integrates the ensemble members forward to time $t_{f}$.

$$
\mathbf{X}_{f}=\left\{M_{f, i}\left(\mathbf{x}_{i}^{\alpha}\right)\right\} \in \mathbb{R}^{n \times N}
$$

with $M_{f, i}$ representing the model operator. In the analysis step at time $t_{f}$, the updated ensemble mean state $\overline{\mathbf{x}}_{a}$ of size $n$, where the operator $\ldots$ represents the ensemble mean, is calculated from the forecast ensemble with

$$
\overline{\mathbf{x}}_{a}=\overline{\mathbf{x}}_{f}+\mathbf{L}_{f} \mathbf{a}_{f}
$$

where the error subspace associated with the forecast ensemble is represented by the columns of $\mathbf{L}_{f}$, which is the transformed forecast ensemble according to:

$$
\begin{aligned}
\mathbf{L}_{f} & :=\mathbf{X}_{f} \mathbf{T} \in \mathbb{R}^{n \times(N-1)}, \\
\mathbf{T} & :=\left(\begin{array}{c}
\mathbf{I}_{(N-1) \times(N-1)} \\
\mathbf{0}_{1 \times(N-1)}
\end{array}\right)-N^{-1}\left(\mathbf{1}_{N \times(N-1)}\right) \in \mathbb{R}^{N \times(N-1)},
\end{aligned}
$$

with the unit matrix $\mathbf{I}$, the null matrix $\mathbf{0}$, and $\mathbf{1}$ is a matrix of ones. The vector of weights $\mathbf{a}_{f}$ has the size $(N-1)$ and is calculated as

$$
\mathbf{a}_{f}=\mathbf{U}_{f}\left(\mathbf{H}_{f} \mathbf{L}_{f}\right)^{T} \mathbf{R}_{f}^{-1}\left(\mathbf{y}_{f}^{o}-\mathbf{H}_{f} \overline{\mathbf{x}}_{f}\right)
$$

with the observation vector $\mathbf{y}_{f}^{o}$ of size $o$ and it's associated measurement operator $\mathbf{H}_{f}$ and observation error covariance matrix $\mathbf{R}_{f} \in \mathbb{R}^{o \times o}$. The matrix $\mathbf{U}_{f}$ is not calculated explicitly. Instead we use the LU-solver DGESV from LAPACK (http://www.netlib.org/lapack/) together with $\mathbf{U}_{f}^{-1}$ :

$$
\mathbf{U}_{f}^{-1}=\rho N^{-1}\left(\mathbf{T}^{T} \mathbf{T}\right)^{-1}+\left(\mathbf{H}_{f} \mathbf{L}_{f}\right)^{T} \mathbf{R}_{f}^{-1} \mathbf{H}_{f} \mathbf{L}_{f} \in \mathbb{R}^{(N-1) \times(N-1)} .
$$


Here $\rho$ represents the forgetting factor, which is proportional to the inverse of the inflation factor described in Anderson and Anderson (1999). Hence, a forgetting factor $\rho$ smaller than 1 results in an artificial inflation of the ensemble spread by a factor larger than 1 .

For the re-initialization the updated ensemble of states is re-sampled according to:

$$
\mathbf{X}_{a}=\overline{\mathbf{X}}_{a}+\sqrt{N} \mathbf{L}_{f} \mathbf{C}_{f}^{T} \mathbf{\Omega}_{f}^{T}
$$

where $\mathbf{C}_{f} \in \mathbb{R}^{(N-1) \times(N-1)}$ is obtained from a Cholesky decomposition applied on $\mathbf{U}_{f}^{-1}$ :

$$
\mathbf{C}_{f} \mathbf{C}_{f}^{T}=\mathbf{U}_{f}^{-1}
$$

and $\Omega_{f}$ is a $N \times(N-1)$ random matrix with orthonormal columns.

Please note that neither the forecast nor the updated error covariance matrix needs to be calculated explicitly, they are replaced according to

$$
\mathbf{P}=\mathbf{L C}^{T} \mathbf{\Omega}^{T} \boldsymbol{\Omega} \mathbf{C L}^{T},
$$

and thus the SEIK analysis and re-initialization (Eqs. 3 and 8) only requires the knowledge of

$$
\begin{aligned}
& \text { the forecast ensemble } \mathbf{x}_{f}^{\alpha} \text {, } \\
& \text { the observation vector } \mathbf{y}_{f}^{o} \text {, } \\
& \text { the observation error covariance matrix } \mathbf{R}_{f} \text {, } \\
& \text { and the forgetting factor } \rho \text {. }
\end{aligned}
$$

In our experiments, we did not use artificial inflation, leaving $\rho=1$. Also, we only use the global variant of the SEIK filter to allow for long-range and cross-parameter covariances, no localization has been applied. 


\subsection{Observations}

We assimilate observations of subsurface temperature and salinity from EN3 (Ingleby and Huddleston, 2007). In one experiment, we supplement the EN3 data with sea surface temperature from HadISST (Rayner et al., 2003), the combined data set is henceforth called EN3/HadISST. The EN3 data are used in the assimilation as unweighted averages per month and grid cell. For any grid cell and any month, all EN3 measurements, which fall within the specific grid cell in the specific month, are averaged to obtain one value per month and grid cell, both for temperature and salinity. The number of measurements within EN3 increased rapidly between 2001 and 2007 with the deployment of autonomous profiling floats from the Argo project (Roemmich et al., 2009). The HadISST data have been regridded to the MPI-ESM grid and supersede any EN3 data at the surface.

With the exception of the ocean surface, observations on a monthly time scale are limited, even in the upper ocean and even in the full Argo era after 2007. Over the entire assimilation period (1996-2010) and on the MPI-ESM grid, EN3/HadISST provides for only $6 \%$ of the grid cells temperature data and for only $3 \%$ of the grid cells salinity data. These numbers slightly improve to $8 \%$ for temperature, and $7 \%$ for salinity, when only the Argo period (2004-2010) is considered (Fig. 1). In addition to the limited spatial coverage, also the temporal coverage is limited: only a few grid cells are covered by observations on at least a yearly basis over the total assimilation time. The temporal coverage improves for the Argo era at depths above $2000 \mathrm{~m}$.

We heuristically chose observation uncertainties of $1 \mathrm{~K}$ for all temperatures and 1 psu for all salinities, so that the SEIK analysis update remains well 
within the physically acceptable bounds of the model $\left(-2^{\circ} \mathrm{C}\right.$ to $40^{\circ} \mathrm{C}$ for temperature and 0 psu to 52 psu for salinity). We also tested smaller uncertainties of $0.1 \mathrm{psu}$ for salinity together with $1 \mathrm{~K}$ for temperature (not shown), as well as depth dependent uncertainties in the range of $0.1 \mathrm{~K}$ to $1 \mathrm{~K}$ for temperature and $0.01 \mathrm{psu}$ to $0.1 \mathrm{psu}$ for salinity (not shown), which showed similar gains during the analysis but more often caused updated temperatures and salinities outside the physically acceptable bounds of the model. In the SEIK filter no limitations are applied to the analysed field. Therefore it may generate unwanted temperatures and salinities while trying to honor sparse observations with small uncertainties, especially in it's global variant and with only 8 ensemble members.

\subsection{Assimilation experiments}

Three experiments are carried out, using the same model setup and the same initial conditions: $(i)$ an unconstrained simulation without assimilation (NoAssim), (ii) an assimilation experiment using all subsurface temperature and salinity observations from EN3 supplemented by HadISST sea surface temperature (AllAssim), and (iii) an assimilation experiment using only subsurface temperature and salinity observations from EN3 below 50 m depth (SubAssim).

The experimental configuration is summarized in Tab. 1. All three experiments are initialized at January 1st, 1996 from the long-term MiKlip baseline-1 assimilation (Pohlmann et al., 2013). Here, anomaly restoring to the European Centre for Medium-Range Weather Forecasts oceanic reanalysis ORAS4 and atmospheric re-analysis ERA and ERA Interim is applied to keep the assimilation close to the climatological state of the model. 
The three experiments consist of eight ensemble members each. The initialization ensembles for all experiments are calculated from a daily data set of baseline-1 in January 1996. For the assimilation experiments we use minimum second order exact sampling (Pham, 2001; Nerger et al., 2005), such that the ensemble mean and covariance matrix of the January 1996 baseline-1 assimilation is exactly represented by the initialization ensemble. This differs slightly from NoAssim, where each of the eight ensemble members has been assigned with the state of the baseline- 1 experiment at the end of days 1 to 8 in January 1996. The analysis is conducted at the end of each month, and only observations from this month are considered in the SEIK update. All experiments are carried out for 15 years (from January 1, 1996 to December $31,2010)$.

\subsection{Model-observation comparison}

In our study our prime interest is in the assimilation of the observed oceanic variability in terms of deviations from the seasonal cycle. For the comparison with observations, we therefore calculate the monthly averaged ensemble mean, which includes the state prior to the analysis step at the end of the month, and remove the mean seasonal cycle and any linear trend for each experiment, except for the Atlantic meridional overturning circulation, see below. Then we compute the root mean square error, RMSE, and correlation coefficient against observations for each grid cell.

We calculate RMSE and correlation coefficients for the global average as well as for regional averages in the following regions: Northern Atlantic Ocean, Indian Ocean, and Niño 3.4. The regions are outlined in Fig. 1.

For each experiment we compute the significance of the calculated RMSE and 
correlation coefficient against observations as following: For each grid cell we apply a bootstrapping scheme with 500 bootstraps of the 15-year monthly averaged ensemble mean. We then calculate the corresponding probability distribution and determine the significance at the $95 \%$ level with a two-tailed test of this distribution.

For sea surface temperature (SST) and potential temperature at $100 \mathrm{~m}$ depth (T100), we compare the simulated temperature field against the observations from EN3/HadISST. Times and grid cells without EN3/HadISST data are omitted. At the surface, in most grid cells the time series consists of 180 points, since there is an observation from HadISST in each month. At $100 \mathrm{~m}$ depth, the time series often consists of less than 10 points, given the lack of sub-surface oceanic observations (Fig. 1a). Here, and also at larger depths, the calculation of a meaningful RMSE or correlation coefficient becomes difficult.

For the ocean heat content (HC700), we compare the simulated heat content from the surface down to $700 \mathrm{~m}$ depth with the heat content data set from the National Oceanic and Atmospheric Administration Ocean Climate Laboratory (NOAA OCL) (Levitus et al., 2012). The NOAA OCL data set comprises seasonal (3 monthly) heat contents, we apply a 3 month averaging to our data accordingly.

For the simulated sea surface height (SSH), we compare our experiments with satellite based measurements of the absolute dynamic topography. The altimeter products were produced by Ssalto/Duacs and distributed by Aviso, with support from CNES (http://www.aviso.altimetry.fr/duacs/), hereafter AVISO. 
We compare the simulated Atlantic meridional overturning circulation (AMOC) time series at $26^{\circ} \mathrm{N}$ from 2004 to 2010 at $1020 \mathrm{~m}$ with the observations from the Rapid Climate Change-Meridional Overturning Circulation and Heatflux Array (RAPID-MOCHA, Cunningham et al. (2007); Smeed et al. (2014)). In the model, the AMOC is derived from the simulated meridional velocity field. There is an overlap of only 6 years between simulations and observations. We therefore do not remove the linear trend nor the seasonal cycle from the simulated AMOC, rather we apply a three months running mean to the time series. We use the ensemble mean time series and its standard deviation to estimate significant changes between the experiments.

\section{Results}

In this section we assess the simulated temperature, ocean heat content, sea surface height and Atlantic meridional overturning circulation in terms of RMSE and correlation coefficient against observations and with reference to the unconstrained experiment NoAssim.

\subsection{Surface temperature}

The observed SST from EN3/HadISST has been directly assimilated in AllAssim, but not in SubAssim. The RMSE of the simulated SST against observations shows similar patterns for all three experiments: large RMSE (>0.7 K) in the Northern Atlantic, equatorial East Pacific, Northwest Pacific, and Southern Ocean, and small RMSE $(<0.7 \mathrm{~K})$ in other regions. The magnitude of the RMSE for the global averaged SST does not differ very much between the two assimilation experiments (AllAssim: 0.55 K, SubAssim: 
$0.59 \mathrm{~K})$. However, it is larger in both assimilations than in the unconstrained experiment NoAssim (0.45 K, Fig. 2 a,c,e), although the latter is not significant at the $95 \%$ level. Areas with significant RMSE values are the tropical Pacific Ocean, and some parts of the Indian Ocean as well. In the Indian Ocean both assimilation experiments degrade the RMSE $(0.47 \mathrm{~K}$ for AllAssim, 0.52 K for SubAssim) compared to NoAssim (0.37 K, Tab 2). In the Niño 3.4 region the RMSE is smaller in the assimilation experiments than in NoAssim: $0.89 \mathrm{~K}$ in AllAssim and 0.82 K in SubAssim, $0.95 \mathrm{~K}$ in NoAssim. In the Northern Atlantic Ocean the RMSE of the assimilation experiments (0.90 K for AllAssim, 1.0 K for SubAssim) is larger than in $\operatorname{NoAssim~}(0.67 \mathrm{~K})$. However, these values are not significant at the $95 \%$ level.

It is not surprising that the RMSE is not improved at every individual grid cell, however, the degradation of the RMSE on the regional and global scale is an issue with regard to the SEIK implementation and will be discussed in Sec. 4.

Compared to the RMSE the patterns for the correlation coefficient of the simulated SST against observations show larger differences between the three experiments (compare Fig. 2 a,c,e and b,d,f). The correlation of the global averaged SST is higher for the two assimilation experiments (0.09 for AllAssim, 0.13 for SubAssim) than for NoAssim (0.06) with a significance level \pm 0.02 (Tab. 2). The improvements in both AllAssim and SubAssim are most prominent in the Tropics, and are generally stronger in SubAssim than in AllAssim. The averaged correlation coefficient in the Niño 3.4 region is 0.14 for NoAssim, 0.38 for AllAssim, and 0.56 for SubAssim with a significance level of \pm 0.13 . In the Northern Atlantic the averaged correlation coefficient 
is degraded due to the assimilation (0.04 in AllAssim, 0.02 in SubAssim, from 0.05 in NoAssim, although all coefficients are too small to be significant $( \pm 0.05))$. In the Indian Ocean only SubAssim (0.14) shows improvement over NoAssim (0.09), the significance level is at \pm 0.04 .

Hence, for SST, the SEIK assimilation does not improve the RMSE against observations, except for the Niño 3.4 region. In contrast, the SEIK assimilations does improve the correlation coefficient against observations on the global average, largest improvements are in the tropical oceans, especially the tropical Pacific. The largest region with degradation is in the Northwestern Pacific in SubAssim (Fig. 2f).

\subsection{Sub-surface temperature}

The observed T100 from EN3 has been directly assimilated in both assimilation experiments. The RMSE of the globally averaged simulated T100 against observations (Fig. 3a,c,e and Tab. 2) is smaller in NoAssim(0.48 K) than in either of the assimilations (0.68 K in AllAssim and 0.74 K in SubAssim). Even in the Niño 3.4 region the RMSE is smaller in NoAssim (0.90 K) compared to AllAssim $(0.95 \mathrm{~K})$ and SubAssim $(1.1 \mathrm{~K})$. However, over most areas the RMSE is not significant in either experiment, which may be caused by the large undersampling in time of the T100 grid cells due to the sparsity of T100 observations. For the same reason the correlation coefficient against observations for T100 is spatially very noisy and not significant for almost any grid cell (Fig. 3b,d,f).

For the three selected regions, the depth profiles down to $500 \mathrm{~m}$ of the area averaged RMSE of simulated temperature against observations show degra- 
dation due to assimilation (Fig. 4a,c,e). In the Northern Atlantic Ocean and in the Indian Ocean the RMSE is for all depths smallest in NoAssim, the difference between AllAssim and SubAssim is negligible. In the Niño 3.4 region the RMSE is improved due to the assimilation only at the surface. For depths below the surface down to $150 \mathrm{~m}$ the RMSE is degraded in AllAssim and even more in SubAssim when compared to NoAssim. Below $150 \mathrm{~m}$, the RMSE is the same in all three experiments. The depth profiles of the area averaged correlation coefficient of simulated temperature against observations (Fig. 4b,d,f) show little difference between the three experiments, except for the upper $100 \mathrm{~m}$ in the Niño 3.4 region, where both assimilation experiments show higher correlation coefficients than NoAssim, and for depths between $200 \mathrm{~m}$ and $300 \mathrm{~m}$ in the Niño 3.4 region, where AllAssim shows higher correlation than both NoAssim and SubAssim.

\subsection{Heat content}

The observed 0-700 $\mathrm{m}$ heat content (HC700) from NOAA OCL has not been directly assimilated in our experiments. The global patterns in HC700 RMSE against observations (not shown) are similar to those from SST in Fig. 2. The SEIK assimilation does not improve the RMSE of the global averaged or the regional averaged HC700, except for a small improvement in SubAssim in the Niño 3.4 region (Tab. 2. The correlation coefficients against observations are shown in Fig. 5. The correlation of the global averaged HC700 is improved due to SEIK assimilation (0.08 for both AllAssim and SubAssim compared to 0.05 for NoAssim), significance level \pm 0.02 . On the regional scale, improvements due to the assimilation are confined to the 
equatorial Pacific, e.g. in the Niño 3.4 region the correlation of the averaged HC700 is 0.30 for AllAssim, 0.45 for SubAssim, against 0.08 for NoAssim, significance level $( \pm 0.22)$. We find degradations in some parts of the Northeastern Pacific and Northeastern Atlantic. The correlation of the averaged HC700 over the Northern Atlantic is 0.09 for AllAssim, 0.08 for SubAssim, from 0.10 for NoAssim, significance level $( \pm 0.05)$.

\subsection{Sea surface height}

The observed SSH from AVISO has not been directly assimilated in our experiments. The RMSE of SSH with respect to observations shows similar patterns and significant areas as the RMSE of SST, they are not shown here. The averaged RMSE for the three selected regions are given in Tab. 2, there is hardly any difference between the three experiments. The global patterns in the correlation coefficient against observations resemble those from SST in an attenuated form (Fig. 6 versus Fig. 2b,d,f). The SEIK assimilation improves the correlation in the global average from 0.05 in NoAssim to 0.09 in both AllAssim and SubAssim, significance level \pm 0.01 . We find most improvements in the tropical oceans, e.g. the correlation of the averaged SSH over the Indian Ocean is increased from 0.00 in NoAssim to 0.12 in AllAssim and 0.13 in SubAssim, significance level \pm 0.04 , and the correlation of the averaged SSH over the Niño 3.4 region is increased from 0.15 in NoAssim to 0.36 in AllAssim and 0.51 in SubAssim, with a significance level of \pm 0.16 . The SEIK assimilation degrades the correlation in some parts of the Northern Pacific, while in the Northern Atlantic there is hardly any difference between the three experiments. 


\section{5. $A M O C$}

The observed AMOC has not been directly assimilated in our experiments. Compared to temperature, HC700, and SSH, the AMOC represents a highly integrated quantity.

The three experiments have a similar 15-year mean AMOC cell (Fig. 7), with the maximum AMOC at $35^{\circ} \mathrm{N}$ and at $1020 \mathrm{~m}$ depth. However, there are noticeable small-scale differences between the three experiments. Firstly, the maximum strength of the AMOC, which is $22 \mathrm{~Sv}$ in NoAssim, $20 \mathrm{~Sv}$ in AllAssim, and $22 \mathrm{~Sv}$ in SubAssim. Secondly, between $20^{\circ} \mathrm{N}$ and $50^{\circ} \mathrm{N}$, the maximum AMOC in SubAssim is generally larger than $20 \mathrm{~Sv}$, whereas it is only $18 \mathrm{~Sv}$ in NoAssim and AllAssim. Thirdly, between $20^{\circ} \mathrm{N}$ and $50^{\circ} \mathrm{N}$, the minimum AMOC of $-2 \mathrm{~Sv}$ is maintained as far as $40^{\circ} \mathrm{N}$ in NoAssim, as far as $50^{\circ} \mathrm{N}$ in AllAssim, but only as far as $25^{\circ} \mathrm{N}$ in SubAssim. As a consequence, between $20^{\circ} \mathrm{N}$ and $50^{\circ} \mathrm{N}$ the boundary between positive and negative simulated AMOC is shifted $100 \mathrm{~m}$ up in AllAssim, but $100 \mathrm{~m}$ down in SubAssim, when compared to NoAssim. There is a noticeable difference in the depth of this boundary between the two assimilations of about $200 \mathrm{~m}$.

As there are no observations available to compare the full AMOC cell with, we now turn to the observed $26^{\circ} \mathrm{N}$ time series from RAPID-MOCHA (Fig. 8a, Tab. 3). The RMSE against observations does not show significant differences between the three experiments $(3.2 \pm 0.4 \mathrm{~Sv}$ for both AllAssim and SubAssim, $3.1 \pm 0.6 \mathrm{~Sv}$ for NoAssim). The correlation with the observed AMOC is decreased in AllAssim $(0.32 \pm 0.16)$ and increased in SubAssim (0.59 \pm 0.17$)$ when compared to NoAssim $(0.42 \pm 0.29)$, but only the improvement of SubAssim over AllAssim is significant. 
In our experiments, we do not expect that an unconstrained atmosphere captures the correct zonal-mean wind variability. It is therefore not surprising that none of our experiments matches the anomalous weak observed AMOC in 2009/2010, which was related to anomalous surface winds in 2009/2010 and the resulting anomalous wind-driven transport.

We remove the direct atmospheric influence on the AMOC at $26^{\circ} \mathrm{N}$ by subtracting the zonal-mean wind driven transport, which is calculated from the simulated zonal wind stress at the ocean's surface (Mielke et al., 2013). Within the three experiments the RMSE of AMOC minus Ekman (Fig. 8b) differs more than the RMSE of the full AMOC. It is smallest in SubAssim with $2.4 \pm 0.1 \mathrm{~Sv}$, compared to $2.6 \pm 0.5 \mathrm{~Sv}$ in NoAssim and $3.1 \pm 0.1 \mathrm{~Sv}$ in AllAssim. The correlation with observations is smaller in AMOC minus Ekman than in the full AMOC. Nevertheless, within the three experiments the correlation of AMOC minus Ekman with observations is improved from $0.23 \pm 0.38$ in NoAssim to $0.28 \pm 0.04$ in AllAssim and $0.41 \pm 0.04$ in SubAssim. Based on the standard deviation, the improvement of both RMSE and correlation against observations in AMOC-Ekman from AllAssim to SubAssim are significant, while the other changes are not significant.

We notice that the standard deviation for RMSE and correlation, along with the ensemble spread, is always larger in NoAssim than in AllAssim and SubAssim, while the difference between the latter two is negligible. For AMOC the standard deviations of NoAssim are larger by a factor of 1.5 to 2, for AMOC minus Ekman by a factor of 5 to 10 (Tab. 3). The SEIK assimilation reduces the RMSE and correlation variability within the ensemble for the AMOC, and even more for AMOC minus Ekman, where the direct 
atmospheric influence is largely reduced.

Summarizing the results, for all analyzed variables there is little improvement over NoAssim due to the SEIK assimilation in the RMSE against observations, but some improvement in the correlation against observations. However, improvements over NoAssim are more often stronger in SubAssim than in AllAssim.

\section{Discussion}

The main questions arising from our results are: Why is the impact of the SEIK assimilations AllAssim and SubAssim, when compared to the unrestricted experiment NoAssim, small on the global scale? Why are improvements from assimilation restricted to the correlation of simulated against observed temperatures and SSH in the tropical oceans, and to correlation improvements in the AMOC and AMOC minus Ekman at $26^{\circ} \mathrm{N}$ in SubAssim? Firstly, the atmosphere in our assimilation is as unconstrained as in NoAssim. Therefore any change of the oceanic fields due to assimilation is quickly offset by the influence of the unconstrained atmosphere, the number of oceanic observations is too small to maintain the gains expected from their assimilation over the whole assimilation interval, this supports the result of (Pohlmann et al., 2009) that there are too few oceanic observations to have an impact. On a monthly scale, the offset is strong in the mid-latitudes, leading to a poorer performance of the assimilation system, and weak in the Tropics, where assimilation gains are retained over the assimilation interval. A shorter assimilation interval than one month would be desirable for the midlatitudes, however, in this case the number of available observations would 
drop even more. Also, the lower atmosphere's high frequency variability may be in conflict with the upper ocean variability, which leads to the significantly poorer performance of AllAssim against SubAssim in terms of SST correlation. A simultaneously constrained atmosphere may help here, but only if it does not destroy the oceanic assimilation effort. The variabilities on both side of the atmosphere-ocean boundary have to be addressed in a reconciled way, which is beyond the scope of our study.

Secondly, we are aware of the fact that we only use a basic setup of the SEIK filter: the ensemble size of 8 is small, together with the global variant of the SEIK filter the covariance matrices are strongly rank-deficient. As a result the filter performance is limited, accounting for analyzed temperatures and salinities being outside the physical bounds of the model, and also accounting for degradation of temperature RMSE on a large scale. A larger ensemble size together with the localized variant of the SEIK filter would be more appropriate.

Thirdly, the uncertainty assigned to the oceanic observations, i.e. their representativeness, needs to be properly utilized for the benefit of a better performance of the SEIK assimilation. For the reason of model stability and setup simplicity we chose uncertainties of $1 \mathrm{~K}$ for temperature and $1 \mathrm{psu}$ for salinity, both independent in time and space. The model uncertainty, which is ultimately calculated from the variability within the simulated ensemble, is smaller than $1 \mathrm{~K}$ or $1 \mathrm{psu}$ at almost any grid cell. Thus, a large weight is put on the model and a small one on the observations. We see two possibilities to put more weight on observations and improve the SEIK performance without compromising the model stability: Firstly, the use of sub-surface observation 
uncertainties based on either the true or modeled representativeness of observations, and secondly, the inflation of the ensemble.

It is also almost certain that the model's preferential oceanic circulation pattern deviates from the one established in the real ocean. An assimilation, which puts too strong an emphasis on the observed state may actually counteract any potential improvement in the circulation pattern. Müller et al. (2015) showed that strong restoring of ocean temperature and salinity to re-analysis data eventually draws the model's state closer to the observed ocean but results in a wrongly simulated AMOC. In this sense, model errors in terms of biases in the circulation cannot and perhaps should not always be corrected too strongly by data assimilation.

Further studies are needed with the ensemble Kalman filter to address the direct assimilation of oceanic observations in a global coupled climate model: the filter setup needs to be improved (including localization), as well as the weighting of the observations and the calibration of the ensemble. However, for a successful oceanic assimilation in a coupled climate model the influence of the atmosphere needs to be properly handled. In the context of coupled data assimilation Zhang et al. (2013) showed that a consistent and balanced atmosphere-ocean constraint is mandatory to initialize predictions, especially on the decadal scale, the corresponding atmosphere-only and ocean-only assimilation, respectively, perform worse than the coupled approach. 


\section{Conclusion}

We assimilate temperature and salinity observations with a global ensemble Kalman filter into the global coupled model MPI-ESM at a monthly time interval over the period 1996 to 2010. Comparing the results of two assimilation experiments and an unconstrained experiment, we conclude:

- For the analyzed quantities, the ensemble Kalman filter assimilation improves the model's sea surface temperature, heat content and sea surface height variability with respect to observations in the tropical oceans. Improvements due to assimilation are largest for the sea surface temperature in the Niño 3.4 region.

- The assimilation experiment that only incorporates oceanic observations below $50 \mathrm{~m}$ depth results in larger improvements of the simulated variability with respect to observations than the assimilation experiment that incorporates oceanic observations over the entire water column. These results suggest that surface variability in a coupled model assimilation with an unconstrained atmosphere can potentially be improved when the boundary between ocean and atmosphere is not too strongly restricted by assimilation, and the variability at the boundary is thus determined by the model dynamics.

- In addition to changes in the directly assimilated temperature field, the assimilation experiment with observations only below $50 \mathrm{~m}$ depth improves the variability of the simulated Atlantic Meridional Overturning Circulation at $26^{\circ} \mathrm{N}$ over the unconstrained experiment. 
Given the basic implementation of the ensemble Kalman filter we used, our study is only the first, and successful, step towards a weakly coupled data assimilation system with the global coupled model MPI-ESM.

\section{Acknowledgements}

We thank three anonymous reviewers for helpful comments. We also thank Luis Kornblueh, Ketan Kulkarni, Helmuth Haak, and Kristina Fröhlich for technical help with the model, and Wolfgang Müller, Holger Pohlmann, and Andreas Hense for many helpful discussions. Temperature and salinities from EN3 and sea surface temperature from HadISST have been retrieved through www.metoffice.gov.uk/hadobs, NOAA OCL heat content data through http://www.nodc.noaa.gov, and AVISO sea surface height data through http://www.aviso.altimetry.fr/duacs. The $26^{\circ} \mathrm{N}$ array is a collaborative effort supported through the UK Natural Environment Research Council (NERC) RAPID-WATCH program, the US National Science Foundation (NSF) Meridional Overturning Circulation Heat-flux Array project, and the US National Oceanographic and Atmospheric Administration (NOAA) Western Boundary Time Series project. Data from the RAPID-WATCH \& MOCHA projects are freely available from www.rapid.ac.uk/rapidmoc and www.rsmas.miami.edu/users/mocha. This research was supported by the German Ministry of Education and Research (BMBF) under the MiKlip project AODA-PENG (grant 01LP1157C; SB, JB) and through the Cluster of Excellence CliSAP (EXC177), University of Hamburg, funded through the German Science Foundation (DFG) (JB). The model simulations were performed at the German Climate Computing Centre (DKRZ). 
Anderson, J. L., Anderson, S. L., Dec. 1999. A Monte Carlo implementation of the nonlinear filtering problem to produce ensemble assimilations and forecasts. Mon. Wea. Rev. 127 (12), 2741-2758.

Branstator, G., Teng, H., 2012. Potential impact of initialization on decadal predictions as assessed for CMIP5 models. Geophys. Res. Lett. 39 (12).

Counillon, F., Bethke, I., Keenlyside, N., Bentsen, M., Bertino, L., Zheng, F., 2014. Seasonal-to-decadal predictions with the ensemble Kalman filter and the Norwegian Earth System Model: a twin experiment. Tellus A 66.

Cox, P., Stephenson, D., 2007. A Changing Climate for Prediction. Science 317 (5835), 207-208.

Cunningham, S. A., Kanzow, T., Rayner, D., Baringer, M. O., Johns, W. E., Marotzke, J., Longworth, H. R., Grant, E. M., Hirschi, J. J.-M., Beal, L. M., Meinen, C. S., Bryden, H. L., 2007. Temporal variability of the Atlantic meridional overturning circulation at $26.5^{\circ}$ N. Science 317 (5840), 935-938.

Forget, G., Wunsch, C., Aug. 2007. Estimated global hydrographic variability. J. Phys. Oceanogr. 37 (8), 1997-2008.

Giorgetta, M. A., Jungclaus, J., Reick, C. H., Legutke, S., Bader, J., Böttinger, M., Brovkin, V., Crueger, T., Esch, M., Fieg, K., Glushak, K., Gayler, V., Haak, H., Hollweg, H.-D., Ilyina, T., Kinne, S., Kornblueh, L., Matei, D., Mauritsen, T., Mikolajewicz, U., Müller, W., Notz, D., Pithan, F., Raddatz, T., Rast, S., Redler, R., Roeckner, E., Schmidt, H., Schnur, R., Segschneider, J., Six, K. D., Stockhause, M., Timmreck, C., 
Wegner, J., Widmann, H., Wieners, K.-H., Claussen, M., Marotzke, J., Stevens, B., 2013. Climate and carbon cycle changes from 1850 to 2100 in MPI-ESM simulations for the Coupled Model Intercomparison Project phase 5. J. Adv. Mod. Earth Sys. 5 (3), 572-597.

Ingleby, B., Huddleston, M., Mar. 2007. Quality control of ocean temperature and salinity profiles - historical and real-time data. J. Marine Sys. 65 (1-4), $158-175$.

Jungclaus, J. H., Fischer, N., Haak, H., Lohmann, K., Marotzke, J., Matei, D., Mikolajewicz, U., Notz, D., von Storch, J. S., 2013. Characteristics of the ocean simulations in the Max Planck Institute Ocean Model (MPIOM) the ocean component of the MPI-Earth system model. J. Adv. Mod. Earth Sys. 5 (2), 422-446.

Karspeck, A. R., Yeager, S., Danabasoglu, G., Hoar, T., Collins, N., Raeder, K., Anderson, J., Tribbia, J., May 2013. An Ensemble Adjustment Kalman Filter for the CCSM4 Ocean Component. J. Climate 26 (19), 7392-7413.

Levitus, S., Antonov, J. I., Boyer, T. P., Baranova, O. K., Garcia, H. E., Locarnini, R. A., Mishonov, A. V., Reagan, J. R., Seidov, D., Yarosh, E. S., Zweng, M. M., 2012. World ocean heat content and thermosteric sea level change (0 - 2000 m), 1955 - 2010. Geophys. Res. Lett. 39 (10).

Mielke, C., Frajka-Williams, E., Baehr, J., 2013. Observed and simulated variability of the amoc at 26n and 41n. Geophys. Res. Lett. 40 (6), 11591164. 
Müller, W., Matei, D., Bersch, M., Jungclaus, J., Haak, H., Lohmann, K., Compo, G., Sardeshmukh, P., Marotzke, J., 2015. A twentieth-century reanalysis forced ocean model to reconstruct the north atlantic climate variation during the 1920s. Climate Dynamics 44 (7-8), 1935-1955.

Nerger, L., Danilov, S., Hiller, W., Schröter, J., 2006. Using sea-level data to constrain a finite-element primitive-equation ocean model with a local SEIK filter. Ocean Dynam 56 (5-6), 634-649.

Nerger, L., Hiller, W., 2013. Software for ensemble-based data assimilation systems - Implementation strategies and scalability. Computers and Geosciences 55, $110-118$.

Nerger, L., Janjić, T., Schröter, J., Hiller, W., Feb. 2012. A Unification of Ensemble Square Root Kalman Filters. Mon. Wea. Rev. 140 (7), 23352345.

Nerger, L., Schröter, J., Hiller, W., 2005. A comparison of error subspace Kalman filters. Tellus A 57 (5), 715-735.

Oke, P. R., Sakov, P., Jun. 2008. Representation error of oceanic observations for data assimilation. J. Atmos. Oceanic Technol. 25 (6), 1004-1017.

Pham, D. T., May 2001. Stochastic methods for sequential data assimilation in strongly nonlinear systems. Mon. Wea. Rev. 129 (5), 1194-1207.

Pham, D. T., Verron, J., Gourdeau, L., 1998. Singular evolutive Kalman filters for data assimilation in oceanography. C. R. Acad. Sci., Ser. II 326 (4), $255-260$. 
Pohlmann, H., Jungclaus, J. H., Köhl, A., Stammer, D., Marotzke, J., Jul. 2009. Initializing decadal climate predictions with the GECCO oceanic synthesis: Effects on the North Atlantic. J. Climate 22 (14), 3926-3938.

Pohlmann, H., Müller, W. A., Kulkarni, K., Kameswarrao, M., Matei, D., Vamborg, F. S. E., Kadow, C., Illing, S., Marotzke, J., 2013. Improved forecast skill in the tropics in the new MiKlip decadal climate predictions. Geophys. Res. Lett. 40 (21), 5798-5802.

Rayner, N. A., Parker, D. E., Horton, E. B., Folland, C. K., Alexander, L. V., Rowell, D. P., Kent, E. C., Kaplan, A., 2003. Global analyses of sea surface temperature, sea ice, and night marine air temperature since the late nineteenth century. J. Geophys. Res. 108 (D14).

Roemmich, D., Johnson, G. C., Riser, S., Davis, R., Gilson, J., Owens, W. B., Garzoli, S. L., Schmid, C., Ignaszewski, M., 2009. The Argo program: Observing the global ocean with profiling floats. Oceanography 22 (2), 34-43.

Smeed, D. A., McCarthy, G. D., Cunningham, S. A., Frajka-Williams, E., Rayner, D., Johns, W. E., Meinen, C. S., Baringer, M. O., Moat, B. I., Duchez, A., Bryden, H. L., 2014. Observed decline of the atlantic meridional overturning circulation 2004-2012. Ocean Science 10 (1), 29-38.

Stevens, B., Giorgetta, M., Esch, M., Mauritsen, T., Crueger, T., Rast, S., Salzmann, M., Schmidt, H., Bader, J., Block, K., Brokopf, R., Fast, I., Kinne, S., Kornblueh, L., Lohmann, U., Pincus, R., Reichler, T., Roeckner, 
629 E., 2013. The atmospheric component of the MPI-M earth system model:

630

631

632

633

634

635 ECHAM6. J. Adv. Mod. Earth Sys. 5 (2), 146-172.

Valcke, S., 2013. The OASIS3 coupler: a European climate modelling community software. Geosci. Model Dev. 6 (2), 373-388.

Zhang, S., Chang, Y.-S., Yang, X., Rosati, A., 2013. Balanced and coherent climate estimation by combining data with a biased coupled model. J. Climate 27 (3), 1302-1314. 
Table 1: Overview of the three experiments carried out. AllAssim: assimilation of EN3/HadISST oceanic temperatures and salinities at all model levels, SubAssim: assimilation of EN3 temperatures and salinities below $50 \mathrm{~m}$ only, NoAssim: no assimilation in the ocean. All three experiments use an identical setup for the remaining components of MPI-ESM. They are all initialized from the January 1996 MiKlip baseline-1 assimilation (Pohlmann et al., 2013).

\begin{tabular}{l|c|c|c}
\hline & AllAssim & SubAssim & NoAssim \\
\hline assim. data & $\begin{array}{r}\text { EN3 and } \\
\text { HadISST }\end{array}$ & $\begin{array}{c}\text { EN3 only } \\
\text { below 50m }\end{array}$ & - \\
\hline assim. interval & 1 month & - \\
\hline init. method & $\begin{array}{r}\text { minimum 2nd order } \\
\text { exact sampling }\end{array}$ & 1 day lagged \\
\hline init. data & January 1996 MiKlip baseline-1 \\
\hline resolution & GR15L40 ocean, T63L47 atmosphere \\
\hline start date & \multicolumn{2}{c}{ 1996-01-01 } \\
\hline end date & 2010-12-31 \\
\hline ens. size & \multicolumn{2}{c}{8} \\
\hline
\end{tabular}


Table 2: RMSE and correlation of area averaged monthly sea surface temperature (SST, against HadISST), monthly $100 \mathrm{~m}$ potential temperature (T100, against EN3), threemonthly 0-700 m heat content (HC700, against NOAA OCL heat content), and monthly sea surface height (SSH, against AVISO) for the three experiments NoAssim, AllAssim, SubAssim. The quantities have been averaged over the globe and over three selected regions: Northern Atlantic Ocean, Indian Ocean, and Niño 3.4 region. The units for RMSE are K (SST, T100), EJ (HC700), cm (SSH). Values, which are not significant at the $95 \%$ level, are written in italics. For each parameter and basin the lowest RMSE and highest correlation coefficient is underlined.

\begin{tabular}{|c|c|c|c|c|c|c|}
\hline & \multicolumn{3}{|c|}{ RMSE } & \multicolumn{3}{|c|}{ correlation } \\
\hline & NoAssim & AllAssim & SubAssim & NoAssim & AllAssim & SubAssim \\
\hline \multicolumn{7}{|l|}{ global } \\
\hline SST & 0.45 & 0.55 & 0.59 & 0.06 & 0.09 & $\underline{0.13}$ \\
\hline $\mathrm{T} 100$ & $\underline{0.48}$ & 0.68 & 0.74 & 0.03 & 0.03 & $\underline{0.05}$ \\
\hline HC700 & 10 & 14 & 15 & 0.05 & 0.08 & $\underline{0.08}$ \\
\hline $\mathrm{SSH}$ & $\underline{6.0}$ & 6.5 & 6.7 & 0.05 & 0.09 & $\underline{0.09}$ \\
\hline \multicolumn{7}{|l|}{ North Atl. } \\
\hline $\mathrm{SST}$ & 0.67 & 0.90 & 1.0 & $\underline{0.05}$ & 0.04 & 0.02 \\
\hline $\mathrm{T} 100$ & $\underline{0.55}$ & 0.93 & 0.94 & -0.01 & -0.01 & 0.03 \\
\hline HC700 & $\underline{7.4}$ & 9.4 & 9.5 & $\underline{0.10}$ & 0.09 & 0.08 \\
\hline $\mathrm{SSH}$ & 7.5 & 8.3 & 8.6 & 0.01 & $\underline{0.05}$ & 0.04 \\
\hline \multicolumn{7}{|l|}{ Indian O. } \\
\hline $\mathrm{SST}$ & 0.37 & 0.47 & 0.52 & 0.09 & 0.09 & $\underline{0.14}$ \\
\hline $\mathrm{T} 100$ & 0.64 & 0.88 & 0.95 & 0.03 & 0.06 & $\underline{0.10}$ \\
\hline $\mathrm{HC} 700$ & 11 & 15 & 16 & 0.00 & 0.10 & $\underline{0.15}$ \\
\hline $\mathrm{SSH}$ & 7.4 & 7.5 & 7.8 & 0.00 & 0.12 & $\underline{0.13}$ \\
\hline \multicolumn{7}{|l|}{ Niño 3.4} \\
\hline $\mathrm{SST}$ & 0.95 & 0.89 & $31 \underline{0.82}$ & 0.14 & 0.38 & $\underline{0.56}$ \\
\hline $\mathrm{T} 100$ & $\underline{0.90}$ & 0.95 & 1.1 & 0.11 & 0.17 & $\underline{0.18}$ \\
\hline HC700 & 15 & 14 & $\underline{13}$ & 0.08 & 0.30 & $\underline{0.43}$ \\
\hline $\mathrm{SSH}$ & 7.5 & 7.1 & 6.7 & 0.15 & 0.36 & $\underline{0.51}$ \\
\hline
\end{tabular}


Table 3: RMSE (in Sv) and correlation of AMOC and AMOC minus Ekman at $26^{\circ} \mathrm{N}$ with respect to RAPID-MOCHA, monthly averaged data 2004-2010 with three month running mean. The experiment with the lowest RMSE and higher correlation coefficient is indicated in bold.

\begin{tabular}{c|c|c|c|c|c|c} 
& \multicolumn{3}{|c|}{ RMSE } & \multicolumn{3}{c}{ correlation } \\
& NoAssim & AllAssim & SubAssim & NoAssim & AllAssim & SubAssim \\
\hline AMOC & $\mathbf{3 . 1}$ & 3.2 & 3.2 & 0.42 & 0.32 & $\mathbf{0 . 5 9}$ \\
spread & $2.8-4.4$ & $2.8-4.0$ & $2.8-4.0$ & $-0.20-0.60$ & $0.04-0.52$ & $0.25-0.69$ \\
std.-dev. & 0.6 & 0.4 & 0.4 & 0.29 & 0.16 & 0.17 \\
\hline AMOC-Ekman & 2.6 & 3.1 & $\mathbf{2 . 4}$ & 0.23 & 0.28 & $\mathbf{0 . 4 1}$ \\
spread & $2.2-3.6$ & $3.0-3.2$ & $2.3-2.6$ & $-0.30-0.60$ & $0.23-0.37$ & $0.32-0.46$ \\
std.-dev. & 0.5 & 0.1 & 0.1 & 0.38 & 0.04 & 0.04 \\
\hline
\end{tabular}


(a) EN3 temperature observations 1996-2010

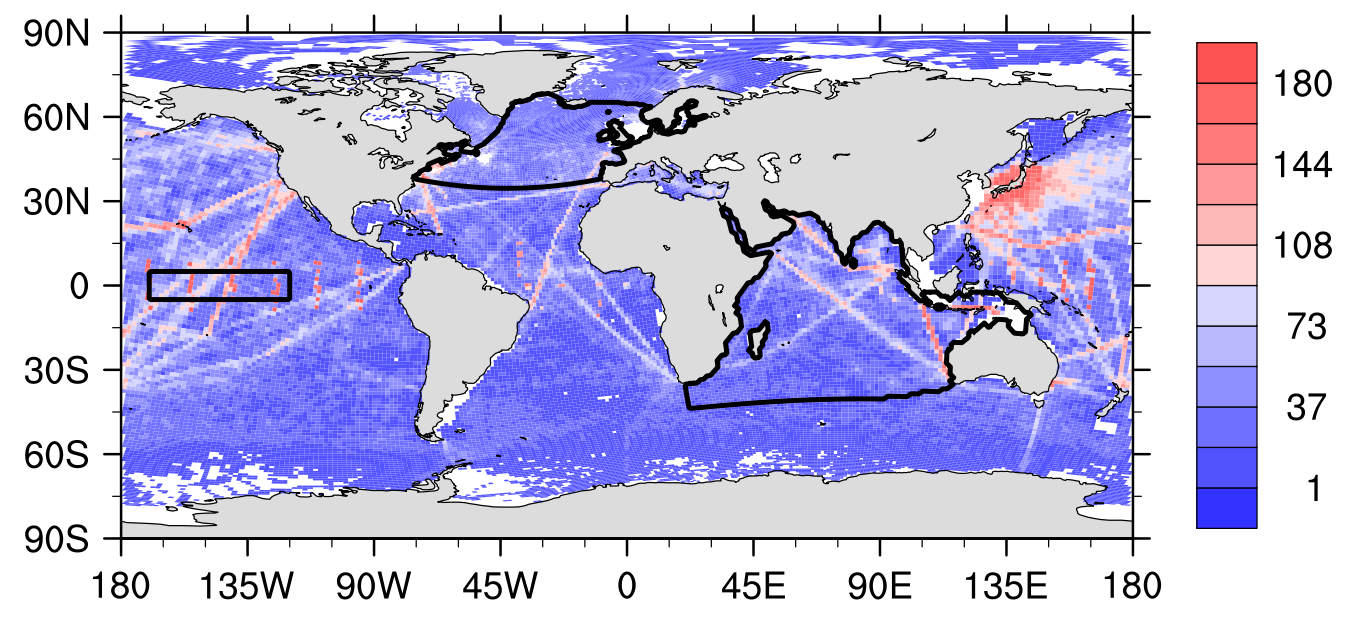

(b) EN3 temperature observations 2007-2010

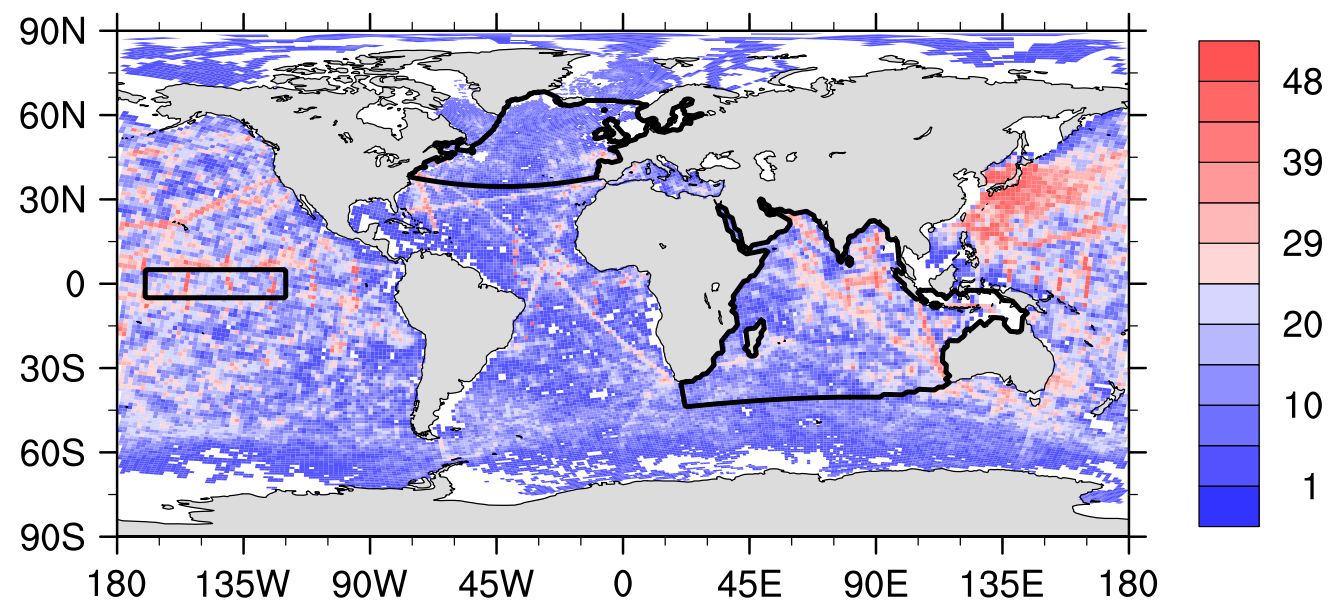

Figure 1: Number of available temperature observations from EN3 at the model's $100 \mathrm{~m}$ level as prepared for the monthly assimilation interval for (a) total assimilation time from January 1996 to December 2010 (180 monthly observations possible), and (b) full Argo era overlapping with our experiments from January 2007 to December 2010 (48 monthly observations possible). White grid cells do not contain any EN3 data. 
(a) SST RMSE NoAssim



(c) SST RMSE AllAssim


(b) SST correlation NoAssim

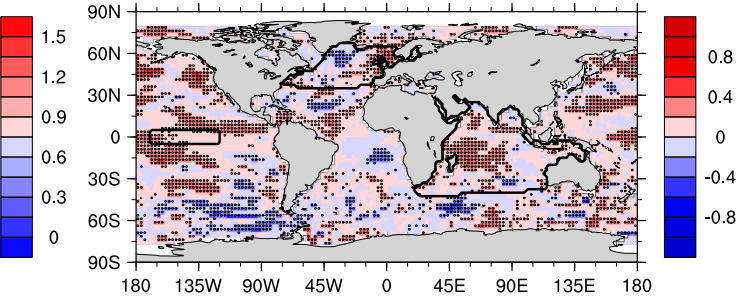

(d) SST correlation AllAssim

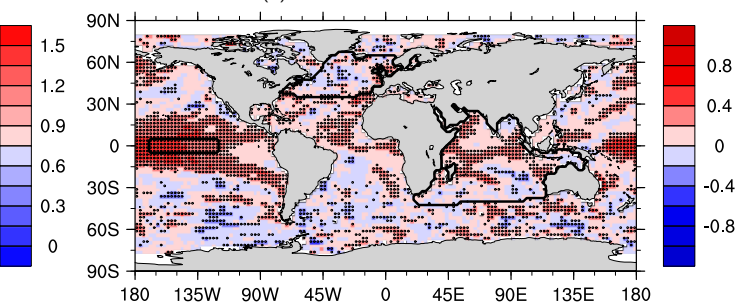

(f) SST correlation SubAssim

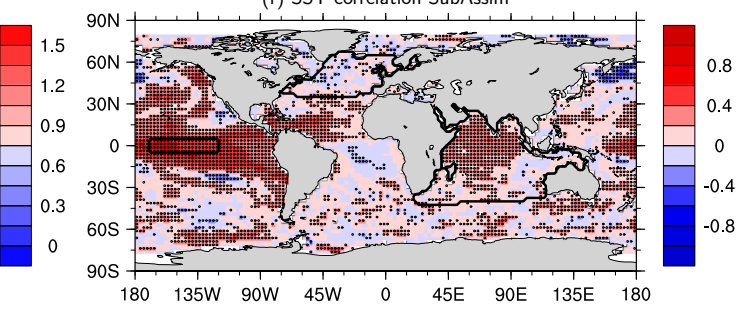

Figure 2: RMSE (a,c,e) and correlation (b,d,f) over 15 years of potential temperature with respect to EN3/HadISST in K at the surface for NoAssim (a,b), AllAssim (c,d), and SubAssim (e,f). Stippling indicates values, which are significant at the $95 \%$ level. White grid cells do not contain any EN3/HadISST data. The black outlines represent the three regions, which have been closer examined: the Northern Atlantic Ocean, the Niño 3.4 region in the equatorial Pacific Ocean, and the Indian Ocean. 
(a) T100 RMSE NoAssim

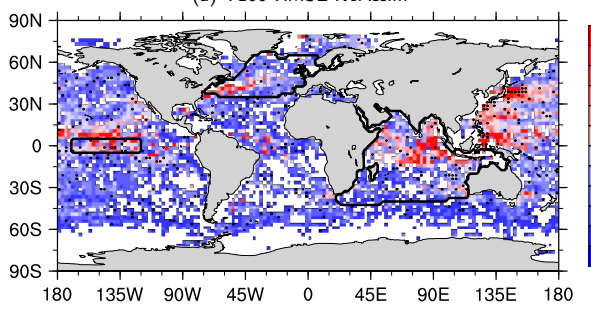

(c) T100 RMSE AllAssim



(e) T100 RMSE SubAssim

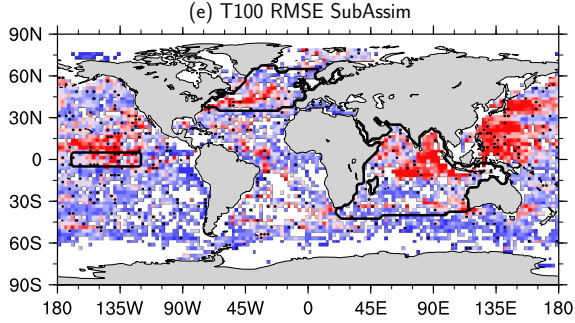

(b) T100 correlation NoAssim

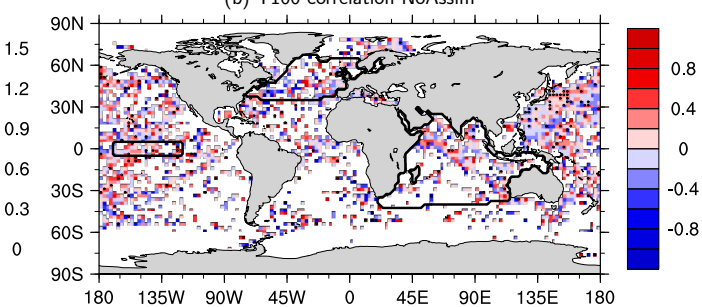

(d) T100 correlation AllAssim



(f) T100 correlation SubAssim

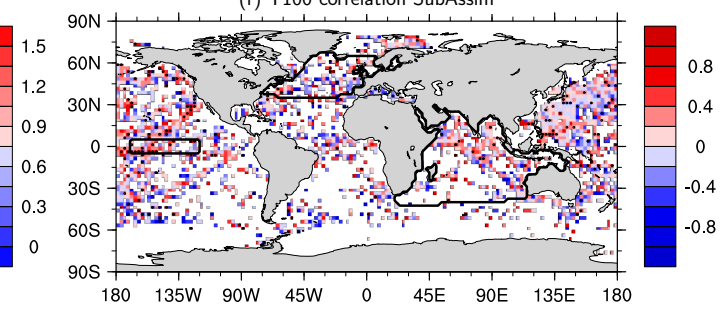

Figure 3: RMSE (a,c,e) and correlation $(\mathrm{b}, \mathrm{d}, \mathrm{f})$ over 15 years of potential temperature with EN3/HadISST at $100 \mathrm{~m}$ depth for NoAssim (a,b), AllAssim (c,d), and SubAssim (e,f). Stippling indicates values, which are significant at the $95 \%$ level. White grid cells do not contain any EN3/HadISST data. The black outlines represent the Northern Atlantic Ocean, the Niño 3.4 region in the equatorial Pacific Ocean, and the Indian Ocean. 
(a) temperature RMSE Northern Atlantic

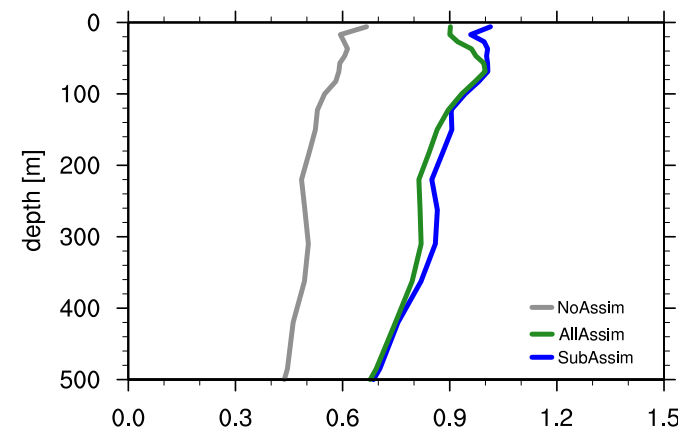

(c) temperature RMSE Indian Ocean

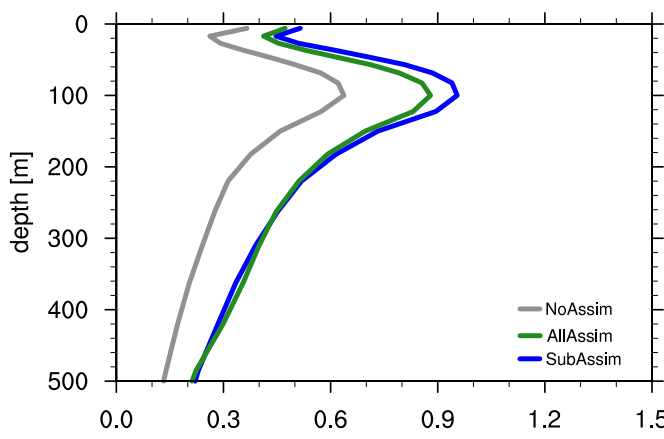

(e) temperature RMSE Niño 3.4

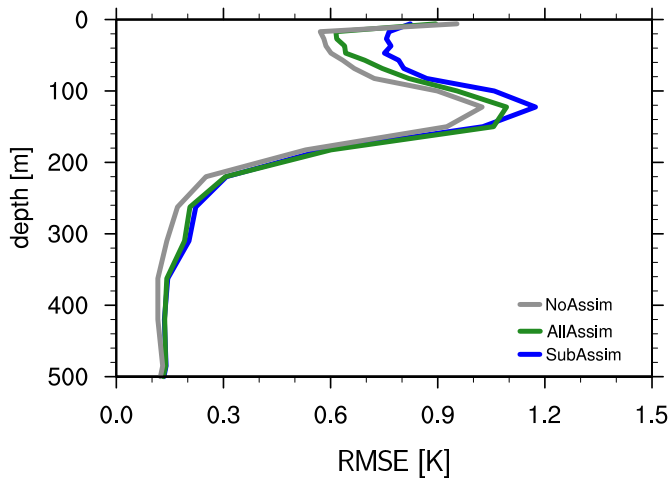

(b) temperature correlation Northern Atlantic

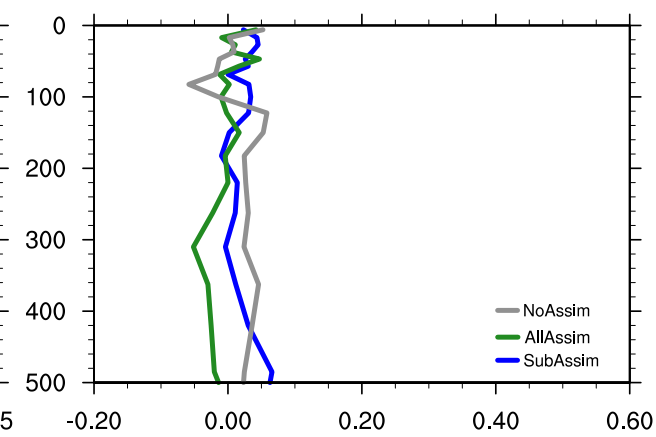

(d) temperature correlation Indian Ocean

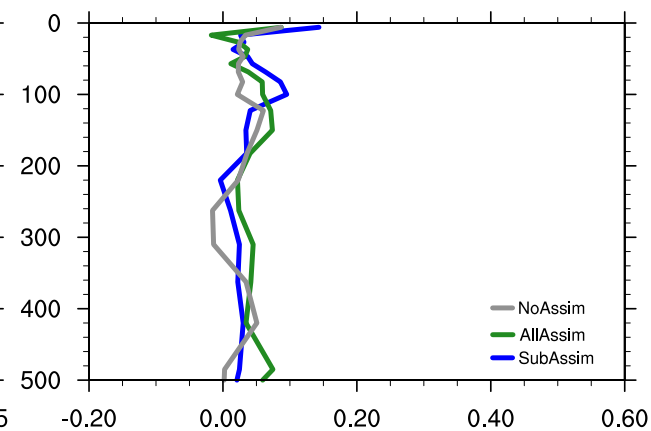

(f) temperature correlation Niño 3.4



Figure 4: Area average of 15-year RMSE (a,c,e, in K) and correlation (b,d,f) of potential temperature with respect to EN3/HadISST for depths down to $500 \mathrm{~m}$ for NoAssim (gray), AllAssim (green), and SubAssim (blue) for the Northern Atlantic Ocean (a,b), the Indian Ocean $(\mathrm{c}, \mathrm{d})$, and the Niño 3.4 region $(\mathrm{e}, \mathrm{f})$. 
(a) HC700 correlation NoAssim

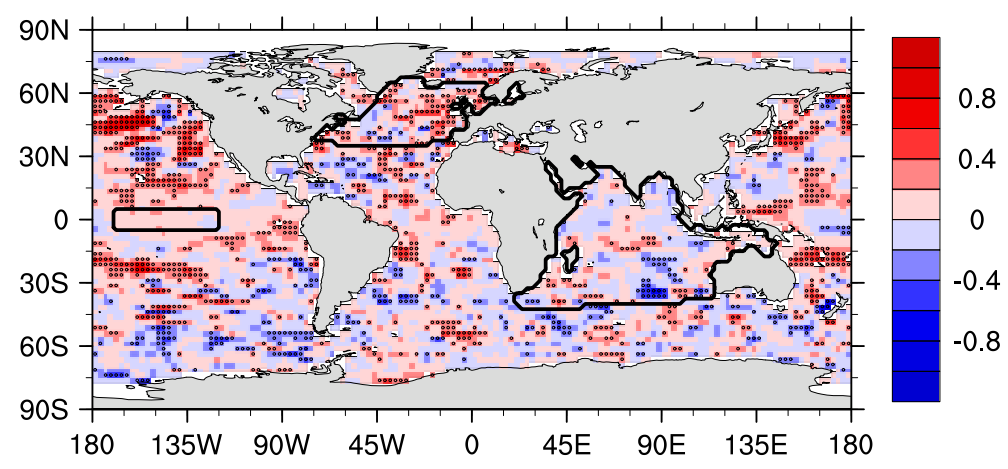

(b) HC700 correlation AllAssim

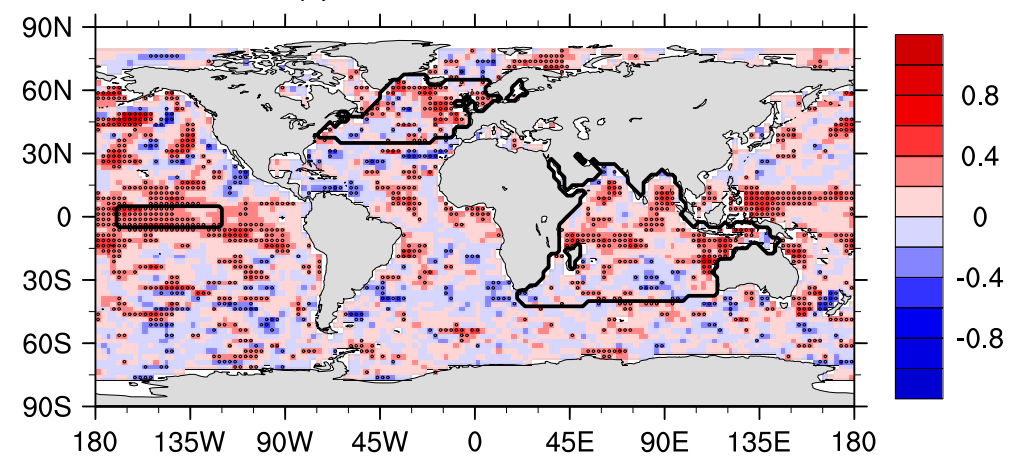

(c) HC700 correlation SubAssim

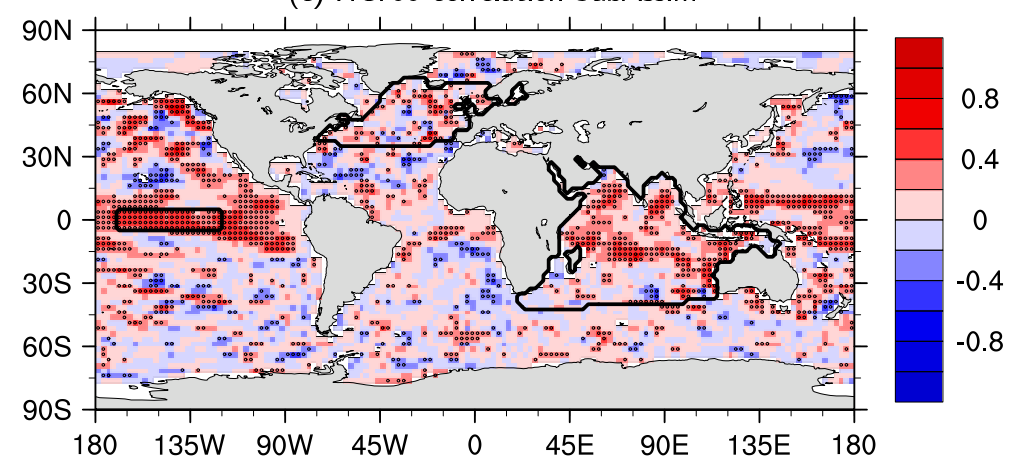

Figure 5: Correlation over 15 years of 3-month average 0-700 $\mathrm{m}$ heat content with NOAA OCL, (a) NoAssim, (b) AllAssim, (c) SubAssim. Stippling indicates values, which are significant at the $95 \%$ level. White grid cells do not contain any NOAA OCL data. The black outlines represent the Northern Atlantic Ocean, the Niño 3.4 region in the equatorial Pacific Ocean, and the Indian Ocean. 
(a) SSH correlation NoAssim



(b) SSH correlation AllAssim

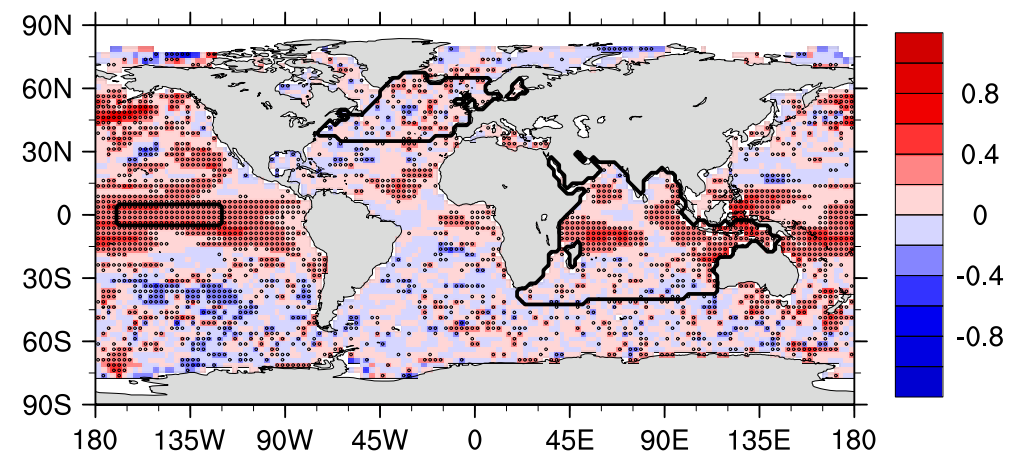

(c) SSH correlation SubAssim

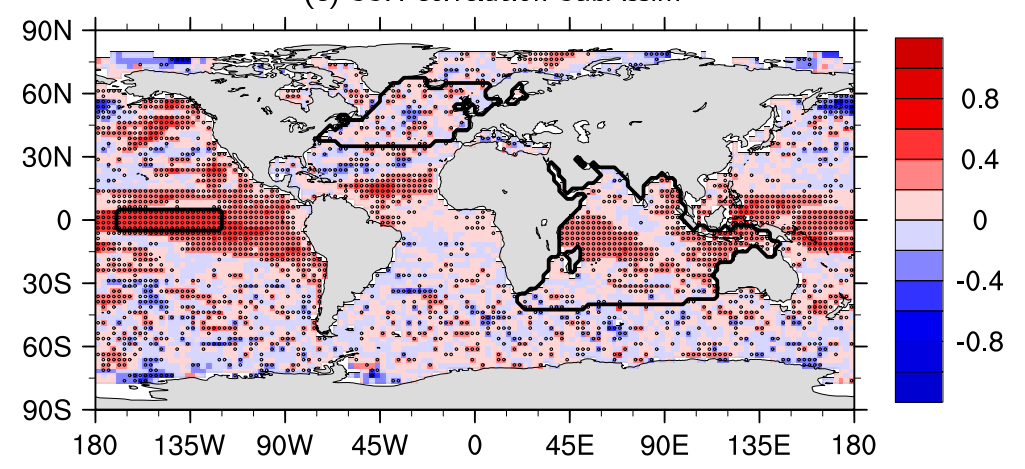

Figure 6: Correlation over 15 years of sea surface height with AVISO, (a) NoAssim, (b) AllAssim, (c) SubAssim. Stippling indicates values, which are significant at the $95 \%$ level. White grid cells do not contain any AVISO data. The black outlines represent the Northern Atlantic Ocean, the Niño 3.4 region in the equatorial Pacific Ocean, and the Indian Ocean. 
(a) 1996-2010 mean AMOC cell NoAssim

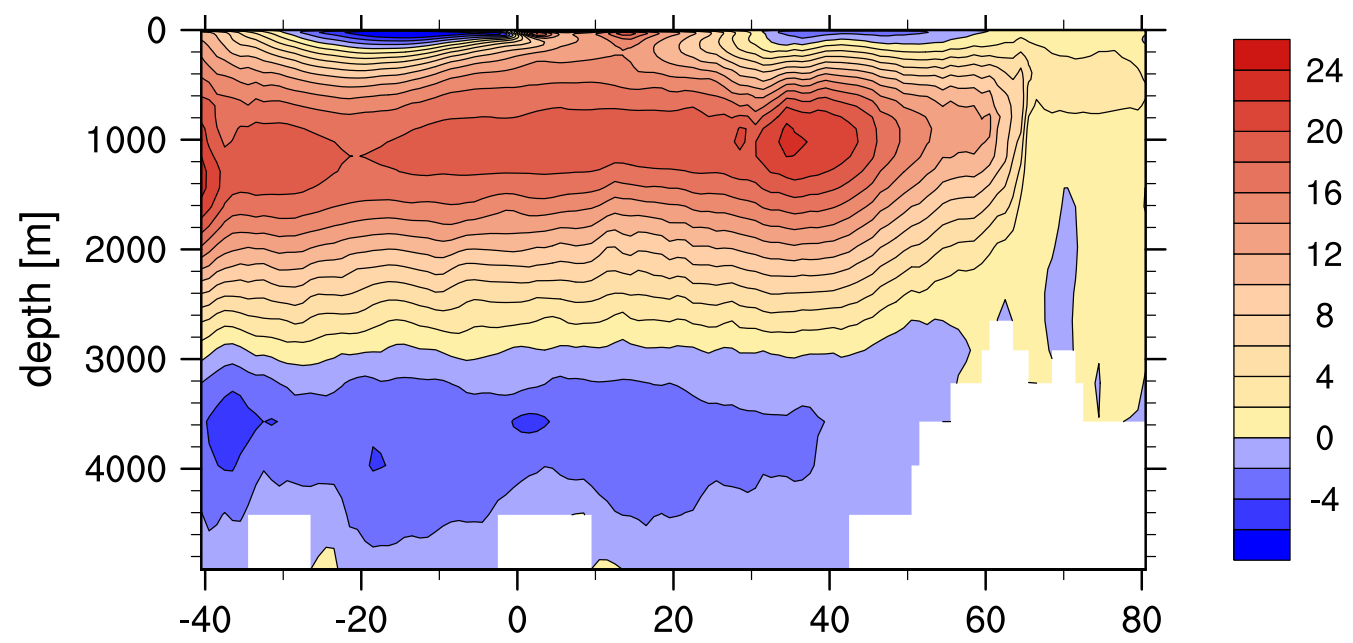

(b) 1996-2010 mean AMOC cell AllAssim



(c) 1996-2010 mean AMOC cell SubAssim

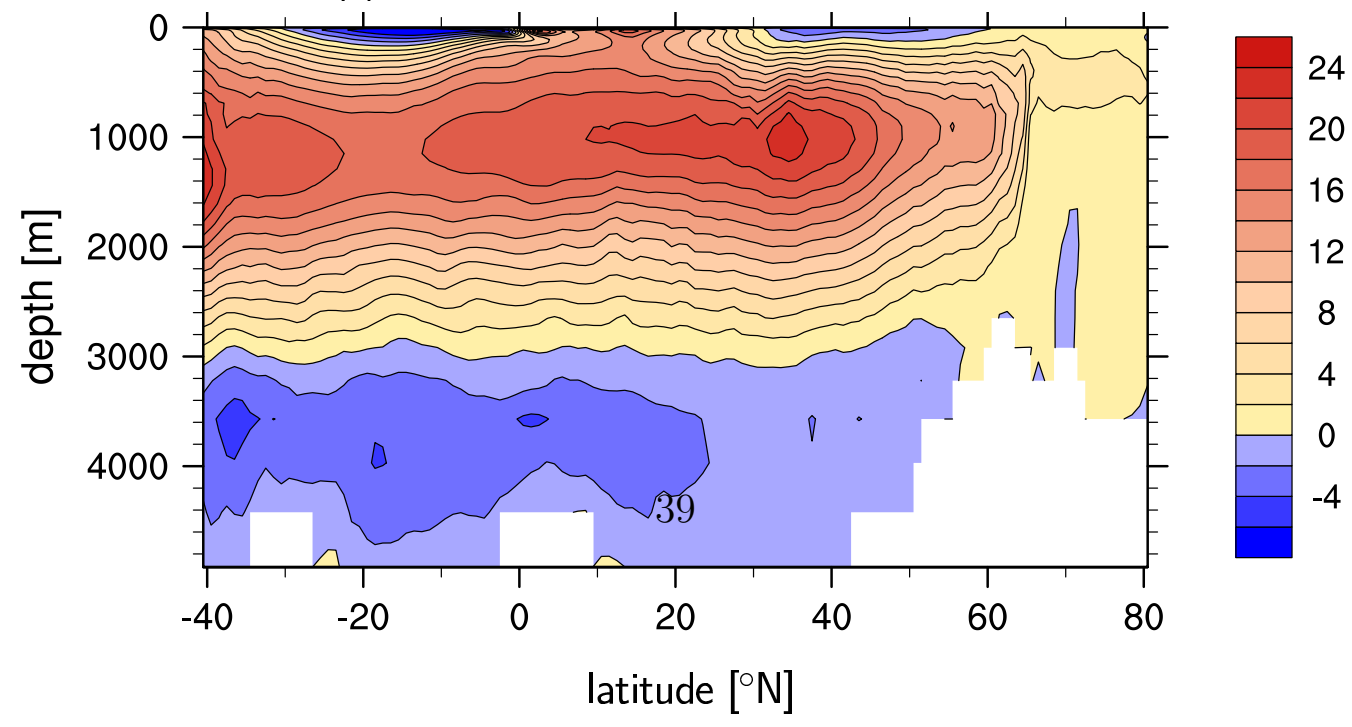

Figure 7: The 15-year mean Atlantic meridional overturning circulation in Sv as simulated 
(a) AMOC at $26^{\circ} \mathrm{N} 2004-2010$

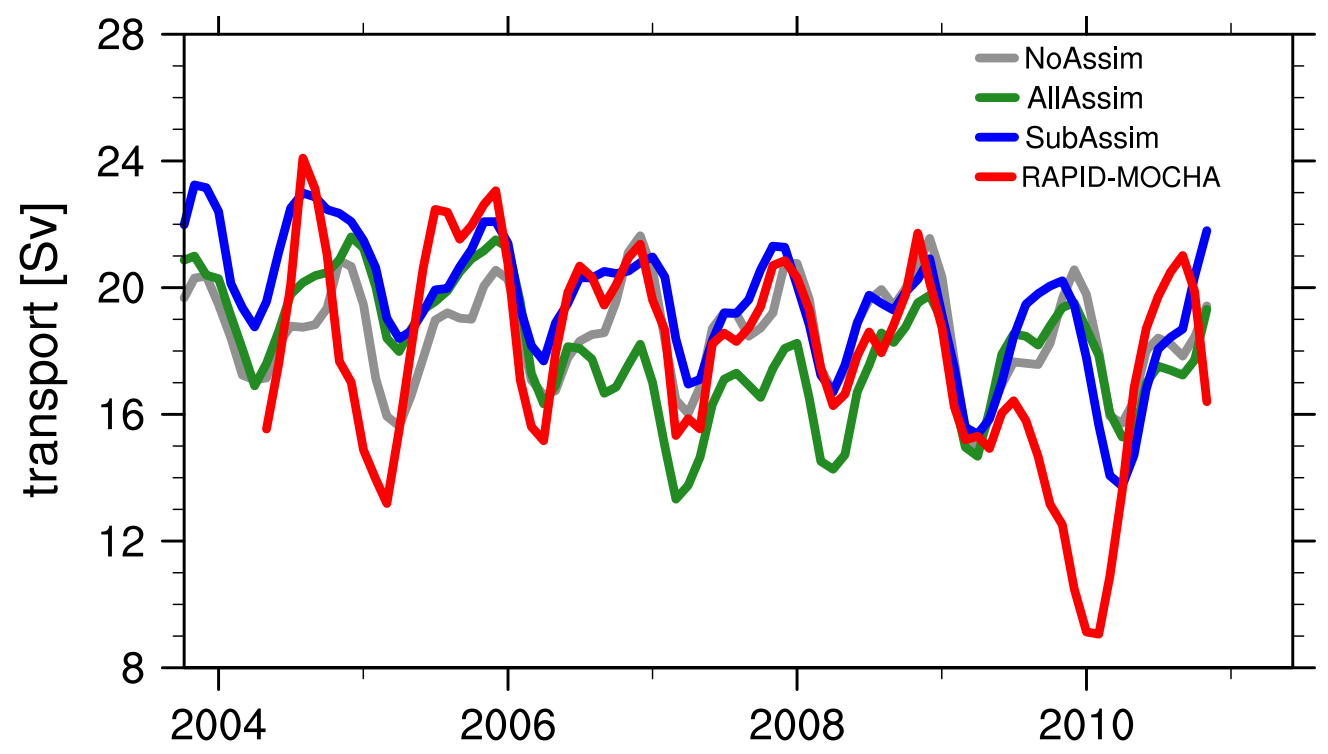

(b) AMOC minus Ekman at $26^{\circ} \mathrm{N} 2004-2010$



Figure 8: (a) Atlantic meridional overturning circulation (AMOC) and (b) AMOC with zonal-mean wind driven transport removed (AMOC minus Ekman) at $26^{\circ} \mathrm{N}$ of NoAssim (gray), AllAssim (green), SubAssim (blue), and observations from RAPID-MOCHA (red, Cunningham et al. (2007); Smeed et al. (2014)). A three month running mean filter has been applied to the monthly data. 